\title{
Methods of Hot Compaction and Infiltration of Powder Materials Based on Recycled Non-Ferrous Alloy Chips
}

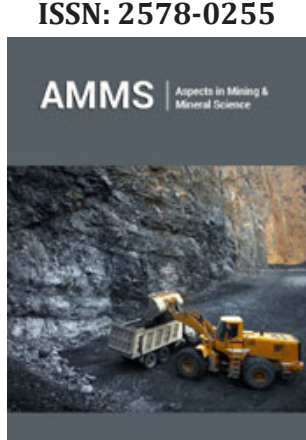

*Corresponding author: Sergey N Sergeenko, Mechanical department, Federal State Budget Educational Institution of Higher Education Russian Federation, Prosveshcheniya, Russia

Submission: 眥 August 19, 2019

Published: 眥 September 30, 2019

Volume 3 - Issue 5

How to cite this article: Sergey N Sergeenko. Methods of Hot Compaction and Infiltration of Powder Materials Based on Recycled Non-Ferrous Alloy Chips. Aspects Min Miner Sci.3(5). AMMS.000572.2019. DOI: 10.31031/AMMS.2019.03.000572

Copyright@ Sergey N Sergeenko, This article is distributed under the terms of the Creative Commons Attribution 4.0 International License, which permits unrestricted use and redistribution provided that the original author and source are credited.

\section{Sergey N Sergeenko*}

Deputy Dean of the Faculty of Mechanics SRSPU (NPI) for scientific work, senior researcher, candidate of technical sciences, Russia

\begin{abstract}
Promising methods have been developed for cold and hot compaction of powder materials, as well as for the infiltration of porous preforms combined with sintering, using chip and dust-like waste from non-ferrous $\mathrm{Al}$ and $\mathrm{Cu}$ alloys as a raw material, as well as utilizable $\mathrm{Cu}$-based powder moldings.
\end{abstract}

Keywords: Compacting; Powder material; Infiltration; Sintering; Chips of Al And Cu alloys; Dusty waste; Recycling

\section{Introduction}

SRSPU (NPI) has developed methods for producing compacted and infiltrated powder materials based on non-ferrous metal shavings $(\mathrm{Al}, \mathrm{Cu})$, as well as sintered materials for the disposal of powder moldings and dusty waste of $\mathrm{Cu}$-based powder blends.

\section{Discussion}

\section{Hot-compacted materials based on mechanically activated Al alloy chips}

Mechanical activation is accompanied by a continuously sequential process of dispersionagglomeration-dispersion, affecting the average size of the powder particles. In this case, three options for particle aggregation are possible: the formation of agglomerates that are destroyed during subsequent manual processing; formation of an active charge, agglomerated during processing in a mortar; the formation of intractable agglomerates. Agglomeration of powder particles of the mixture is carried out by: flow of topochemical reactions along the front of particle interaction; setting on the contact surfaces of the particles; sharpening the material of soft particles with solid particles and cladding solid particles with a layer of material of soft particles [1,2]. At the first stage of activation in a saturated aqueous solution of $\mathrm{H}_{3} \mathrm{BO}_{3}$, Al-based charges proceed with the evolution of $\mathrm{H}_{2} \mathrm{O}$

$$
\mathrm{H}_{3} \mathrm{BO}_{3} \rightarrow \mathrm{HBO}_{2} \rightarrow \mathrm{B}_{2} \mathrm{O}_{3}
$$

An increase in the duration of mechanical activation leads to the enveloping of $\mathrm{B}_{2} \mathrm{O}_{3}$ chip particles, forming a coating $\mathrm{mAl}_{2} \mathrm{O}_{3} \mathrm{nB}_{2} \mathrm{O}_{3}$, which prevents the interaction of $\mathrm{Al}$ with oxygen, prevents the melting of $\mathrm{Al}$ during short-term heating and promotes compaction during hot compaction. With the introduction of graphite into the mixture, exothermic reactions may occur.

$$
\begin{gathered}
13 \mathrm{Al}+12 \mathrm{HBO}_{2} \rightarrow \mathrm{AlB}_{12}+6 \mathrm{Al}_{2} \mathrm{O}_{3}+6 \mathrm{H}_{2} \mathrm{O} \\
4 \mathrm{Al}+\mathrm{C}+4 \mathrm{HBO}_{3} \rightarrow 2 \mathrm{Al}_{2} \mathrm{O}_{3}+\mathrm{B}_{4} \mathrm{C}+2 \mathrm{H}_{2} \mathrm{O} \\
4 \mathrm{Al}+4 \mathrm{Al}_{2} \mathrm{O}_{3}+3 \mathrm{C} \rightarrow 3 \mathrm{Al}_{4} \mathrm{O}_{4} \mathrm{C}
\end{gathered}
$$

The mechanical activation of the mixture in a liquid medium contributes to a shift in the dynamic equilibrium of competing dispersion-agglomeration processes towards the destruction of the initial particles of Al alloy chips and alloying elements, as well as agglomerates based on them due to the Rebinder effect - absorption strength reduction. The hereditary effect of dispersion-agglomeration processes on the laws of compaction and formation of the structure and properties of powder materials was established [3,4]. Upon receipt of hot-compacted materials with increased bending strength (620MPa) based on 
crushed chips of $\mathrm{Al}$ alloy, mechanochemical activation is carried out in a saturated aqueous $\mathrm{H}_{3} \mathrm{BO}_{3}$ solution followed by cold and hot compacting [5]. Processing a mixture of activated chips (50 wt.\%) And $\mathrm{Al}$ powder in a planetary ball mill in a saturated aqueous $\mathrm{H}_{3} \mathrm{BO}_{3}$ solution provides a hot compacted material with a density of $2.91 \mathrm{~g} /$ $\mathrm{cm}^{3}$, shear strength $369 \mathrm{MPa}$ and bending $325 \mathrm{MPa}$, hardness HRB 96 with specific wear of $0.2 \mu \mathrm{m} / \mathrm{km}$ and a friction coefficient of 0.09 in the conditions of boundary friction (pressure in the contact zone of 8.7MPa) [6]. In order to reduce the cost of starting materials in the manufacture of parts for structural purposes, a method for mechanical alloying carbon alloy Al. The technology includes mechanochemical activation (3.6ks) of $\mathrm{Al}$ alloy shavings in a saturated aqueous $\mathrm{H}_{3} \mathrm{BO}_{3}$ solution (20\% of the mass of the charge), mechanical alloying with carbon during joint processing (5.04ks) of activated shavings with graphite ( $2 \mathrm{wt} . \%$ ) In ball planetary mill, subsequent cold compaction with a pressure of 120MPa, heating (973K; $0.12 \mathrm{ks}$ ) in an air atmosphere and hot compaction with a reduced compaction work of $55 \mathrm{MJ} / \mathrm{m}^{3}$. The hot compacted material had a density of $2.84 \mathrm{~g} / \mathrm{cm}^{3}$, a shear strength of $250 \mathrm{MPa}$ and a hardness of HRB 65 [7]. The introduction of Ni or FeTi powders into a mixture based on $\mathrm{Al}$ alloy chips intensifies its grinding processes, providing the formation of hot-compacted materials with enhanced mechanical properties. The technology for producing the material includes mechanochemical activation of $\mathrm{Al}$ alloy chips together with $\mathrm{Ni}$ or FeTi powder in a saturated aqueous $\mathrm{H}_{3} \mathrm{BO}_{3}$ solution, separation of a fraction of less than $315 \mu \mathrm{m}$, its subsequent mixing with Al powder, and hot compaction [8,9].

\section{Compacted materials based on mechanically activated Cu alloy chips}

In order to obtain antifriction material based on $\mathrm{Cu}$ powder during utilization of the chips of the $\mathrm{Cu}$ alloy, a method is proposed that includes mechanical activation of the chips, preparation of the mixture, compaction of powders (400MPa), sintering (1253K; $8.1 \mathrm{ks}$ ) of the workpiece in a protective medium, followed by its cold compaction (600MPa). The mechanical activation (10.8ks) of the chips is carried out in the attritor with the mass ratio of balls and chips of 27:1, followed by the isolation of a fraction of less than 315 microns. The mixture is prepared on the basis of a mixture of powders of $\mathrm{Al}(9$ wt.\%), $\mathrm{Fe}(4 \mathrm{wt} . \%), \mathrm{Cu}$ (ost.) And powdered mechanically activated shavings of $\mathrm{Cu}$ alloy (8 wt.\%). The technology provides a cold compacted powder material with a flexural strength of $560 \mathrm{MPa}$ and a bend angle of $25^{\circ}$ [10].

\section{Infiltrated composite powder materials}

In order to reduce the cost of obtaining low-porous powder materials during utilization of chips of $\mathrm{Cu}$ alloys, a method for melt infiltration of a low-melting porous refractory skeleton material with a melt has been developed. The technology includes two-stage cold compaction of a bimetallic billet (low-melting infiltrate 34 wt.\% - refractory frame based on Fe) by pressing (610MPa) chip briquette of the infiltrate, followed by pressing (410MPa) of Fe powder. The resulting laminated preform is sintered (1423K; $9.0 \mathrm{ks}$ ) in a glass melt with simultaneous melt impregnation of the chips. Composite infiltrated material has a tensile strength of $370 \mathrm{MPa}$
[11]. Upon receipt of low-porosity (5.2\%) materials with increased bending strength $(760 \mathrm{MPa})$, preliminary pressing $(200 \mathrm{MPa})$ of iron powder is carried out, followed by pressing (600MPa) of brass briquette (25 wt.\%) And sintering combined with infiltration [12].

\section{Sintered powder materials}

In order to increase the efficiency of the technology for producing powder materials by using dusty wastes of $\mathrm{Cu}$-based charges, a method is proposed that includes preparing the charge, cold compaction of the preform and its sintering. At the first stage, grinding $(6.3 \mathrm{ks})$ in the attritor of FeMn powder is carried out, screening is not associated with FeMn balls, mechanically activating the dusty waste of the powder mixture based on $\mathrm{Cu}$ by treating (6.3ks) with balls coated with FeMn during its grinding in the attritor. At the second stage, a mixture is prepared consisting of a mixture of $\operatorname{Sn}(9$ wt.\%), Graphite(5 wt.\%) And Cu(ost.) Powders, as well as an activated additive of $16 \mathrm{wt} . \%$. Then carry out cold compaction (280MPa) and sintering (1123K; $7.2 \mathrm{ks}$ ) of the workpiece in a protective environment. The developed technology ensures the utilization of pulverized wastes of $\mathrm{Cu}$-based powder blends and an increase in the strength (180MPa) of sintered material during radial compression tests [13]. When disposing of waste based on Cu-based powder moldings, pre-ground $(\sim 5 \mathrm{~mm})$ and kerosene-impregnated waste powder moldings are activated in a high-energy mill using grinding balls coated with FeMn. The technology intensifies the grinding of powder molding wastes [14].

\section{Conclusion}

The paper gives a brief overview of promising methods for hot compaction of Al-based powder materials with the addition of "chip" powder obtained by mechanochemical activation of chips of an $\mathrm{Al}$ alloy. For the disposal of chips from $\mathrm{Cu}$ alloys, technologies have been developed for cold compaction and dosed infiltration from a pressed chip briquette. The possibility of using pulverized waste as a raw material obtained by mixing a mixture based on $\mathrm{Cu}$ powders, as well as the disposal of defective $\mathrm{Cu}$-based powder moldings, is shown.

\section{References}

1. Sergeenko SN, Alabid NS (2016) Hot-deformed powder materials based on mechanochemically activated charges Al-SiC. Tsvetnye Metally (9): 68-77.

2. Sergeenko SN (2019) Kinetics of dispersion-agglomeration processes during mechanical activation of the charge of 110G13 powder steel. Chernye Metally (7): 47-52.

3. Dorofeev YG, Bezborodov EN, Sergeenko SN (2003) Special features of formation of compacted material from mechanochemically activated fining of aluminum alloy $D_{1} 6$. Metal Science and Heat Treatment 45(12): $73-75$.

4. Dyuzhechkin MK, Sergeenko SN, Popov YV (2016) Features of structure and property formation for hot-deformed materials of the Al-Si and Al-SI-C systems based on mechanochemically activated charges. Metallurgist 59(9-10): 835-842.

5. Pat. $2216434 \mathrm{RU}$

6. Pat. $2234393 \mathrm{RU}$

7. Pat. $2234395 \mathrm{RU}$ 
8. Slabkii DV, Sergeenko SN (2016) Hot-deformed Al-Ni powder materials based on alloy D-16 mechanically-activated turnings. Metallurgist 59(11): 1228-1233.

9. Fedoseeva MA, Sergeenko SN (2015) Structure and properties of AlFeTi powder material based on mechanochemically activated alloy D16 turnings. Metallurgist 59(5-6): 535-539.

10. Pat. 2061581 RU
11. Pat. $2336146 \mathrm{RU}$

12. Pat. $2167741 \mathrm{RU}$

13. Pat. 2458165 RU

14. Pat. 2458166 RU

For possible submissions Click below: 